\title{
"Side effects-part of the package" - A mixed methods approach to adverse events among patients with DR-TB under RNTCP Gujarat, India
}

Arjunkumar Hardas Jakasania ( $\nabla$ aarrjjuunn999@Gmail.com )

Mahatma Gandhi Institute of Medical Sciences https://orcid.org/0000-0003-3749-1993

Kalpita Shringarpure

Baroda Medical College

Dixit Kapadia

District Tuberculosis office Ahmedabad

Radhika Sharma

BJ Medical College

Kedar Mehta

GMERS Medical College Gotri Vadodara

Arpit Prajapati

Gujarat Cancer Society Medical College

Soundappan Kathirvel

Post Graduate Institute of Medical Education and Research

\section{Research article}

Keywords: Adverse event, Drug resistant tuberculosis, Operational research, Incidence, India, Treatment seeking

Posted Date: July 13th, 2019

DOI: https://doi.org/10.21203/rs.2.10941/v2

License: (a) (1) This work is licensed under a Creative Commons Attribution 4.0 International License. Read Full License 


\section{Abstract}

Background: Unsuccessful treatment outcomes among patients with drug resistant tuberculosis (DR-TB) are due to high rates of adverse events (AEs). However, information related to AEs is not systematically collected and managed under programmatic setting. The present study assessed the a) incidence and pattern of adverse events in first three months of DR-TB treatment initiation; $b$ ) treatment seeking behaviour for AE management; and c) explore the challenges in seeking treatment and reporting AEs. Methods: This mixed methods study included all patients diagnosed and initiated on treatment under RNTCP during July-September 2018 at Ahmedabad DR-TB centre. The patients were interviewed telephonically and assessed for all AEs experienced by them. In-depth interviews and key-informant interviews were conducted among patients, DOTS supervisors and programme staffs (treatment supervisors, medical officer and district program manager). Results: A total 207 AEs were reported by the 74 DR-TB patients. All patients experienced at least one AE during initial treatment period. Incidence rate of AEs (experienced) was 3.11 (1 st month-4.6, 2nd month-2.7, 3rd month-2.02) per 100 person days. Of the 207 AEs, gastro-intestinal $(59,28.3 \%)$, ophthalmic $(32,15.4 \%)$ and otolaryngology $(25,11.9 \%)$ system related AEs were commonly experienced. Treatment was not sought in two-fifths of the AEs. Themes and subthemes related to challenges in treatment seeking or reporting of AEs were 1) Patient relatedMisconceptions, accessibility and affordability of management, lack of counselling support, stigma and discrimination, and past treatment experience; 2) Health system related- lack of guideline and training for AE management, and poor coordination between hospital and tuberculosis centre. Conclusion: The incidence of AEs was high among patients with DR-TB in the first three months of treatment and treatment seeking/reporting was low. Adequate health education and counselling of the patient and orientation of the health systems are the need of the hour. An efficient real-time reporting and management of $A E$ can be developed and tested for effective DR-TB control.

\section{Background}

Tuberculosis (TB) is the leading infectious cause of death and still continues to be a major public health problem. The emerging issue of Drug-resistant Tuberculosis (DR-TB) due to inappropriate treatment regimens, poor quality drugs and inadequate intake of first-line Anti-TB drugs has worsened the situation; making its management quite a challenge (1). Globally, an estimated 558000 people with TB were resistant to the most effective first-line drug i.e., rifampicin (RR-TB), and of these, $82 \%$ had multidrugresistant TB (MDR-TB) in 2017. Similarly, an estimated $3.5 \%$ of new cases and $18 \%$ of previously treated cases had MDR/RR-TB globally and India shares nearly one fourth of the estimated cases (2).

India, a high burden DR-TB country has rolled out the programmatic management of drug resistant TB (PMDT) in 2007 and covered all parts of the country by 2013 (3).Over a period, the country implemented the World Health Organization's (WHO) ambulatory care model and changed from criteria-based drug sensitivity testing (DST) to universal DST to detect and treat the DR-TB to address the DR-TB burden. Now, patients with DR-TB are treated with various DR-TB regimens and shorter DR-TB regimen (based on Bedaquiline and Delaminid) has also been introduced under expanded access in the country. This is due 
to low successful treatment outcomes (47\%) with the conventional regime and vice versa with the shorter regime (4).

Higher proportion of patients with DR-TB are encountering adverse events (AEs) due to long duration of treatment, use of second line anti-tuberculosis drugs, multi-drug use, long duration of injections and other patient related characteristics (5). It was reported that $20-100 \%$ of patients with DR-TB had undergone at least one $A E$ involving gastro-intestinal tract, hepato-biliary, neurological, oto-vestibular, eye, musculoskeletal and other systems; with symptoms ranging from mild to severe and some serious adverse reactions (6-9). However, anecdotal evidence has shown that the reporting of AEs by patients is low; which can end up in severe AEs and impact treatment outcome. Studies have reported the association of AEs with poor medication adherence and unsuccessful treatment outcomes like loss to follow up, treatment failure and death $(10,11)$.

There is a large variation observed between studies reporting the number of events and proportions of DRTB patients with AEs, as most of the studies relied on medical record data abstraction (8-10,12-15). This could be an underestimation; especially in the context of developing countries like India, where the primary importance is given on diagnosis and initiation of treatment rather than identification, management and reporting of all AEs by the health systems and poor treatment seeking behavior of patients. Such low reporting of AEs experienced by patients with the health systems further remains unmanaged.

As there is limited information available on the exact burden of AEs experienced by the patients with DRTB in Indian context, we assessed the incidence and pattern of AEs experienced by patients with DR-TB, their health seeking behavior and factors associated with non-reporting of AEs under programmatic setting.

\section{Methods}

\section{Study Design}

A mixed methods study (sequential explanatory design) with quantitative-retrospective cohort study through record review and patient interviews and qualitative-descriptive design was used. The qualitative findings were used to supplement the quantitative data.

\section{Study setting}

General setting: The study was conducted in Ahmedabad district of Gujarat state, India. There are 34 DR district tuberculosis centers (DTC) in the state which have notified 2266 DR-TB cases in the year 2018 (16). Treatment success rate for patients with DR-TB was reported to be $43 \%$ and loss to follow up was $15 \%$ in the year 2017. The Ahmedabad district (including Ahmedabad municipal area and rural area) has a population of $7,045,314$ including $5,633,927$ population of Ahmedabad city, which makes it the most populous city in Gujarat and the fifth most populous in India $(16,17)$. 
Ahmedabad DR-TB center: The DR-TB Centre in Ahmedabad is situated in State TB demonstration and training centre (STDC), Civil Hospital campus, Ahmedabad. The state nodal DR-TC and Intermediate state reference laboratory is also situated within the campus. It has facility for solid culture and drug susceptibility testing (DST), liquid culture and DST and Line probe Assay (LPA) and Cartridge Based Nucleic Acid Amplification Test (CBNAAT). Patients diagnosed with DR-TB are put on conventional treatment regimen, Universal drug sensitivity guided treatment regimen and Bedaquiline containing treatment regimen. There is a TB and Chest ward which is attached with the centre with advanced treatment facilities (16).

\section{Study site:}

DR TB Centre attached to tertiary care hospital in Central Gujarat.

\section{Study population:}

For quantitative study, all patients initiated on DR-TB treatment between $1^{\text {st }}$ July to $30^{\text {th }}$ September 2018 and having completed the first three months of treatment under the Revised National Tuberculosis Control Program (RNTCP) at the DR-TB Center, Ahmedabad, Gujarat were included in the study. Interviews were conducted in the fourth month of their treatment. Those patients who were 'loss to follow up' were also included irrespective of 'treatment taken' duration. Those patients a) who did not consent for the interviews; b) transferred out to other district DR-TB center and c) on Bedaquiline regimen were excluded.

For the qualitative component, in-depth interview (IDI) was conducted among conveniently selected patients and DOTS providers. Key-informant interview (KII) was conducted among medical officers, DR-TB supervisor and district programme managers.

\section{Data collection and analysis}

A list of patients with DR-TB, who were diagnosed and/or initiated on treatment during $1^{\text {st }}$ July 2018 to $30^{\text {th }}$ September 2018 were obtained from DR-TB center. Further, relevant information like name, address, and contact number, date of initiation of treatment, drug resistance status, name of designated DOTS provider and Senior TB supervisor and data on AEs were abstracted from treatment cards. The patients were telephonically interviewed once at end of third month of treatment initiation for AEs experienced by them month wise in the last three months using a semi-structured questionnaire. The details collected during the interview were noted down using electronic data collection tool (KoBo Collect v1.14) (19).If any $\mathrm{AE}$ was experienced by them in past three months, details like the month of $\mathrm{AE}$ occurrence, classification of system involved (including the symptoms) as per International Council for Harmonisation of Technical Requirements for Pharmaceuticals for Human Use-ICH classification (20) with expert recommendation which has been used in various studies $(5,21)$; and whether treatment was sought for the reported AE were noted. Socio-demographic characteristics like age, gender, residence (urban/rural), occupation, education 
and clinical characteristics like co-morbidities (HIV, Diabetes mellitus and other chronic conditions) and addiction (tobacco and alcohol), previous TB history were collected. The information related to healthcare provider from whom patient is taking daily injections (Auxiliary nurse midwife/qualified Private practitioner / unqualified private practitioner/ primary health centre-medical officer/other) was also obtained.

The data extracted through record review were entered in the excel. The data collected through the electronic data capture tool was downloaded, merged with extracted data in excel and exported to EpiData version 2.2.2.182 for analysis (EpiData Association, Odense, Denmark). Incidence of AEs has been reported as 100 person days month wise and for total duration of three months of initial treatment. Number and proportion were calculated for gender, occupation, residence, per capita income, characteristics of the patients like HIV status, DM status, addiction (tobacco, alcohol), past history of TB, patients with DR-TB on treatment experienced $A E$, pattern of $A E s, A E s$ reported and its pattern, type of healthcare facility and healthcare providers contacted for management of AEs. Age was reported in mean (Standard deviation). A p-value of 0.05 was considered statistically significant. The findings have been reported using strengthening the Reporting of Observational studies in Epidemiology (STROBE) guidelines (22).

For qualitative data: The principal investigator, trained and experienced in qualitative research methods conducted IDIs among patients after consent during their quantitative interview, using an interview guide. The interview explored the views and experiences of the patients related to DR-TB treatment and AEs. Similarly, this also explored their treatment seeking behavior and "emic" view (patient perspective) on facilitators and barriers of seeking medical assistance from healthcare providers. IDIs and KII were also conducted among purposively selected health care providers using interview guide in local language and each interview lasted for nearly 15-20 minutes. Verbatim notes were taken during the interview. Transcripts were made on the same day of the IDI based on the verbatim notes by co-field investigator. The transcripts obtained were compiled and the PI read the transcripts to become familiar with the data. Manual descriptive content analysis was used to analyze the transcripts. It was reviewed by a second investigator (KS) to reduce bias and interpretive credibility. The decision on coding rules and theme generation were done by using standard procedures and in consensus (23). Any difference between the two were resolved by discussion. The findings have been reported by using 'Consolidated Criteria for Reporting Qualitative Research (COREQ) guidelines (24).

Ethical Issues: Ethical approval was obtained from the Institutional Ethics Committee of the B. J. Medical College, Ahmedabad, India, and the Ethics Advisory Group of the International Union against Tuberculosis and Lung Disease, Paris, France. A verbal informed consent was obtained from the patients and the stakeholders for interviews and confidentiality has been maintained.

\section{Results}

\section{Quantitative}


During July-September 2018, a total of 74 eligible patients were interviewed among 128 patients registered and put on treatment at the study site (Figure 1). The mean (SD) age of participants was 32.4 $(+13.6)$ years. Of the 74 patients, $44(59.5 \%)$ were male; $46(62.2 \%)$ were educated up to secondary school; $54(73 \%)$ belonged to below poverty line; 60 (81.1\%) were residing in urban area; and $64(86.5 \%)$ had tuberculosis in the past. The socio-demographic, behavioral and clinical characteristics of the participants are given in table 1. A total of $22(29.7 \%)$ patients were tobacco users (either smokeless or smoking) and $24(32.4 \%)$ reported presence of at least one comorbidity.

All 74 patients experienced at least one adverse event during the first three months of treatment and a total of 207 events were reported. The incidence rate of AEs (per 100 person days) during the study period was 3.11 (4.6, 2.7 and 2.02 for the first, second and third month from initiation of treatment respectively). System wise AEs have been described in figure 1. AEs related to gastro-intestinal, ophthalmic and otolaryngology were the commonly experienced among 59 (28.3\%), 32 (15.4\%) and $25(11.9 \%)$ times respectively among patients. The pattern and month wise distribution of AEs is depicted in figure 2 .

Of the 207 AEs experienced by patients, treatment was sought for 124 (61.7\%) AEs (Figure 1). Patients were categorized as 'having sought treatment' if they reported more than $50 \%$ of experienced AEs, 'not having sought treatment' if they reported less than $50 \%$ of experienced AEs. None of the patient characteristics were significantly associated with the patient not seeking treatment (Table 2).

\section{Qualitative:-}

To further explore the factors for low treatment seeking or reporting of AEs and to identify challenges from patient's and health care provider's perspective, exploratory qualitative interview was carried out with patients and health care providers. Twenty patients with DR-TB (14 male and six female) and eight DOTS providers (six Urban, two Rural), two medical officers and two DOTS plus supervisors and senior TB treatment supervisors (one from rural and urban each) and two programme managers at district tuberculosis centre were interviewed.

The perceptions regarding adverse events in DR-TB treatment and treatment seeking behaviour for AE management from patients and health care provider perspective were coded under 12 codes organised into four categories. These four categories were grouped into two broad themes a) Health system related challenges and $b$ ) Patient-related challenges and listed in table 3.

\section{Discussion}

The present study highlights adverse events (AEs) among patients with DR-TB, one of the most important factors associated with drug adherence in DR-TB (25-27). All 74 patients experienced at least one AE during the three months of treatment duration; GIT, ophthalmology and otolaryngology organ systems were most commonly involved. The incidence rate of AEs (per 100 person days) during the study period was 3.11 (4.6, 2.7 and 2.02 for the first, second and third month from initiation of treatment respectively). 
Findings of our study are relevant and novel for a country like India where rate of MDR and LTFU is very high (2). Several studies have been conducted on AEs during DR-TB treatment till date which were mainly record-based, but discordance between AEs experienced by patients and reported in clinical records have been reported by various studies for TB as well as other diseases (28-32). To our best knowledge, the present study is the first to assess comprehensively the incidence and pattern of AEs experienced among patients with DR-TB using a patient centered approach, treatment seeking behavior for its management and factors associated with treatment seeking. Mixed methods design of the study is an additional strength of our study which explored the challenges in seeking treatment for AEs and reporting the same from both the patients and treatment providers perspective.

The findings related to pattern of AEs are consistent with previous studies $(14,15,25,33)$. Our study reported higher incidence of AEs compared to other studies conducted in India. This could be due to direct reporting of $A E s$ by the patients rather extraction from records which might have missed events $(9,10,34)$. However, patients have tendency to overreport side effects on being interviewed and this may have contributed to higher incidence.

Higher proportion of AEs occurring in the first month of treatment in this study is in congruence with the pharmacological assumption of increased AEs in the first few months and days of treatment initiation (35). In studies done elsewhere in India and globally, higher proportion of AEs were reported in later months of treatment initiation. The likely reason could be a reporting bias as record based studies might miss the AEs in initial months either by the patients or by health systems.

In our study for two fifths of AEs, patients did not contact any health care providers (HCP) for treatment and thus remained unreported in program records. Missed and/or unreported AEs hamper the pharmacovigilance system recommended by WHO (36), which focuses on management and prevention of AEs in tuberculosis. Delayed or nonreporting of AEs to health care facility can miss a serious AEs and this can further lead to LTFU or permanent disabilities or death (37). Regular follow up of patients and an enquiry into AEs, its reporting by HCPs and counsellors may improve reporting and management.

None of the demographic, clinical and behavioural characteristics were associated with treatment seeking behaviour. However, qualitative finding reflected various factors like misconceptions for AEs and its management, accessibility and affordability of management, lack of counselling support, past treatment experience being responsible for not seeking care. Furthermore knowledge regarding adverse events and importance of identification and early management was found to be low not only in patients but also in health care providers and these findings are consistent with other studies (38-40). Misconception regarding tuberculosis and adverse events were evident among health care providers similar to studies conducted in Gujarat and India $(39,41,42)$. Affordability and accessibility of higher centre for diagnosis and treatment also plays an essential role in reporting and seeking care as most of the patients belong to lower socio-economic status or lose their job due to TB (43).Trainings and specific guidelines for identification, management and proper referral for further treatment was the felt need of the HCPs. 
Our study is not without limitations. The information obtained regarding AE episodes were subjective and not cross-verified with any clinical evidence. However, it has been quoted that self-reported history by patients is the best source to capture any clinical event including AEs (44). We understand the possibility of recall bias in our study which could be low due to a) interview was done by an doctor; and b) systematic application of questionnaire and probing. Interpretation of the study findings needs caution as it studied small sample size and single DR TB centre. However, experience of AEs in all patients and low reporting reflects the ground situation which warrants further multicentric studies. In addition, the data is important in the local context in terms of identifying the training needs and counseling approach. Absence of visual clues and probing due to telephonic conversation could have compromised rapport and resulting under/over reporting of AEs is another limitation of our study. However, telephonic conversation provided a better platform to discuss sensitive topics and allowed the health care providers to respond to the programmatic challenges without hesitations.

Present study emphasizes on missed adverse events by the health systems. This may guide policy makers to sensitize and train all health care providers under RNTCP for AE and effective management. Counselling of patients at the time of initiation of treatment, and regular visit and systematic reporting of AE can be included in the treatment approach. Objective and real time assessment of AEs can be planned for further practice change. The pathway of care for $A E$ can be studied to improve the understanding of treatment seeking behavior of the patients before establishing any independent AE management system in the program.

\section{Conclusions}

The incidence of AEs was high among patients with DR-TB in the first three months of treatment and treatment seeking/reporting was low. Adequate health education and counselling of the patient and orientation of the health systems are need of the hour. An efficient real-time reporting and management of $A E$ can be developed and tested for effective DR-TB control.

\section{Abbreviations}

Not applicable

\section{Declarations}

\section{Ethics approval and consent to participate}

Ethics approval obtained from the Institutional Ethics Committee of the B. J. Medical College, Ahmedabad, India, and the Ethics Advisory Group of the International Union against Tuberculosis and Lung Disease, Paris, France and informed verbal consent was obtained from all participants.

\section{Consent for publication}




\section{Availability of data and material}

The datasets used and/or analysed during the current study are available from the corresponding author on reasonable request.

\section{Acknowledgement}

This research was conducted as a part of the 'National Operational Research Training Course 2018-19' organised by Project Axshya, funded by The Global Fund and implemented by The International Union Against Tuberculosis and Lung Diseases (The Union), South-East Asia Regional Office, New Delhi, India. The training course was conducted in collaboration with Revised National Tuberculosis Control Program, Ministry of Health and Family Welfare, Government of India and National Institute for TB and Respiratory Diseases, New Delhi, India.

The training is based on "The Union/Medécins sans Frontières (MSF)" model OR course and has been acknowledged/accredited by the Special Programme for Research and Training in Tropical Diseases at the World Health Organization (WHO/TDR) under SORT IT (Structured Operational Research and Training Initiative). Mentorship and facilitation for this course was provided through The Union South-East Asia Office, New Delhi; the Centre for Operational Research, The Union, Paris, France; Medical College Baroda, Vadodara; Médecins Sans Frontières, New Delhi; ESIC Medical College and PGIMSR, Bengaluru; North Delhi Municipal Corporation Medical College, Hindu Rao Hospital, New Delhi; GMERS Medical College, Vadodara; Postgraduate Institute of Medical Education and Research, Chandigarh, India; Yenepoya Medical College, Mangalore.

We would like to acknowledge the time and inputs given by patients and support of the Head of the Department, Preventive and Social Medicine, B.J. Medical College, Ahmedabad and the staff of District TB Office for their incessant support throughout the study period.

\section{Funding}

The training course under which this research was conducted and open access publication charges was funded by, The Global Fund to Fight AIDS, Tuberculosis and Malaria (GFATM). The funders had no role in study design, data collection and analysis, decision to publish, or preparation of the manuscript.

\section{Competing interests}

The authors declare that they have no competing interests. 


\section{Authors' contributions}

AJ, KSS, SK KM, AP, DK made substantial contributions to conception and design of the project. AJ, KSS, $\mathrm{SK}, \mathrm{KM}, \mathrm{AP}, \mathrm{DK}, \mathrm{RS}$, made substantial contributions to the acquisition of data and analysis and interpretation of data. All authors were involved in drafting the manuscript or revising it critically for important intellectual content. All authors have given final approval of the version to be published. Each author participated sufficiently in the work to take public responsibility for appropriate portions of the content; and agrees to be accountable for all aspects of the work.

\section{References}

1. Paul R. The Threat of Multidrug-resistant Tuberculosis. J Glob Infect Dis. 2018;10(3):119-20.

2. World Health Organization (WHO). WHO I Global tuberculosis report 2018. WHO [Internet]. 2019 [cited 2019 May 2]; Available from: https://www.who.int/tb/publications/global_report/en/

3. RNTCP. Guideline for PMDT in India 2017:: Central TB Division [Internet]. [cited 2019 May 2]. Available from: https://tbcindia.gov.in/index1.php?lang=1\&level=2\&sublinkid=4780\&lid=3306

4. RNTCP. TB India Report $2018::$ Ministry of Health and Family Welfare [Internet]. [cited 2019 May 2]. Available from: https://tbcindia.gov.in/showfile.php?lid=3314

5. Avong YK, Isaakidis P, Hinderaker SG, Van Den Bergh R, Ali E, Obembe BO, et al. Doing no harm? Adverse events in a nation-wide cohort of patients with multidrug-resistant tuberculosis in Nigeria. PLoS One. 2015 Mar 17;10(3):1-15.

6. Patel S V., Nimavat KB, Alpesh PB, Shukla LK, Shringarpure KS, Mehta KG, et al. Treatment outcome among cases of multidrug-resistant tuberculosis (MDR TB) in Western India: A prospective study. J Infect Public Health. 2016 Jul 1;9(4):478-84.

7. Vashrambhai Patel S, Kapil Bhikhubhai N, Bhimabhai patel A, Samrat Shringarpure K, Gautambhai Mehta K, Krishnakumar Shukla L, et al. Adverse Drug Reactions in Patients put on Multi Drug Resistant Tuberculosis (MDR-TB) Treatment in Seven Districts of Central Gujarat. J Young Pharm. 7.

8. Hoa NB, Nhung NV, Khanh PH, Hai NV, Quyen BTT. Adverse events in the treatment of MDR-TB patients within and outside the NTP in Pham Ngoc Thach hospital, Ho Chi Minh City, Vietnam. BMC Res Notes. 2015;8(1):4-9.

9. Patil S, Bhagwat $\mathrm{R}$, Mohite $\mathrm{R}$, Barphe $\mathrm{S}$. Profile of adverse drug reactions in multiple drug resistant tuberculosis patients at drug resistant-tuberculosis center - Miraj, Maharashtra. Int J Med Sci Public Heal. 2016;6(4):1.

10. Suryawanshi SL, Shewade HD, Nagaraja SB, Nair SA, Parmar M. Unfavourable outcomes among patients with MDR-TB on the standard 24-month regimen in Maharashtra, India. Public Heal Action. 
11. Sengul A, Akturk UA, Aydemir Y, Kaya N, Kocak ND, Tasolar FT. Factors affecting successful treatment outcomes in pulmonary tuberculosis: A single-center experience in Turkey, 2005-2011. J Infect Dev Ctries. 2015;9(8):821-8.

12. Sadiq S, Khajuria V, Tandon VR, Mahajan A, Singh JB. Adverse drug reaction profile in patients on antitubercular treatment alone and in combination with highly active antiretroviral therapy. $\mathrm{J}$ Clin Diagnostic Res. 2015;9(10):FC01-4.

13. Tag El Din MA, El Maraghy AA, Abdel Hay AHR. Adverse reactions among patients being treated for multi-drug resistant tuberculosis at Abbassia Chest Hospital. Egypt $\mathrm{J}$ Chest Dis Tuberc [Internet]. 2015;64(4):939-52. Available from: http://dx.doi.org/10.1016/j.ejcdt.2015.03.004

14. Rathod KB, Borkar MS, Lamb AR, Suryavanshi SL, Surwade GA, Pandey VR. Adverse events among patients of multi drug resistant tuberculosis receiving second line anti TB treatment. Int J Sci Reports. 2015;1(6):253.

15. Kapadia VK, Tripathi SB. Adverse drug reactions and outcome analysis of MDR TB patients on DOTS plus regimen. Natl J Community Med. 2016;7(1):5-9.

16. State TB Cell. RNTCP Performance report Gujarat 2018 Third quarter [Internet]. [cited 2019 May 2]. Available from: https://nhm.gujarat.gov.in/images/pdf/3-Quarter-2018-RNTCP-Performance-Report.pdf

17. Office of the Registrar General \& Census Commissioner I, Ministry of Home Affairs, Government of India. CENSUS 2011 India report [Internet]. [cited 2019 May 2]. Available from: http://www.censusindia.gov.in/2011census/PCA/PCA_Highlights/pca_highlights_file/India/Chapter-1.pdf

18. Deborah Rosenbaum FS. Clinical Research Monitor Handbook: GCP Tools and Techniques, Second Edition - CRC Press Book [Internet]. CRC Press ; 1998 [cited 2019 May 2]. Available from:

https://www.crcpress.com/Clinical-Research-Monitor-Handbook-GCP-Tools-and-Techniques-SecondEdition/Rosenbaum-Smith/p/book/9780429132032

19. KoBoToolbox | Data Collection Tools for Challenging Environments [Internet]. [cited 2019 May 21]. Available from: https://www.kobotoolbox.org/

20. ICH Guidelines Implementation: ICH [Internet]. [cited 2019 May 27]. Available from: https://www.ich.org/products/ich-guidelines-implementation.html

21. Isaakidis P, Varghese B, Mansoor H, Cox HS, Ladomirska J, Saranchuk P, et al. Adverse events among HIV/MDR-TB co-infected patients receiving antiretroviral and second line anti-TB treatment in Mumbai, India. PLoS One. 2012;7(7). 
22. STROBE Statement-checklist of items that should be included in reports of observational studies [Internet]. [cited 2019 May 2]. Available from: http://www.epidem.com/

23. J. S. The Coding Manual for Qualitative Research. [Internet]. Los Angeles, CA, USA: SAGE Publications; 2010. Available from: http://stevescollection.weebly.com/uploads/1/3/8/6/13866629/saldana_2009_thecoding-manual-for-qualitative-researchers.pdf

24. Tong A, Sainsbury P, Craig J. Consolidated criteria for reporting qualitative research (COREQ): a 32item checklist for interviews and focus groups. Int J Qual Heal Care. 2007 Sep 16;19(6):349-57.

25. Lv X, Tang S, Xia Y, Wang X, Yuan Y, Hu D, et al. Adverse Reactions Due to Directly Observed Treatment Strategy Therapy in Chinese Tuberculosis Patients: A Prospective Study. PLoS One. 2013;8(6):1-8.

26. Deshmukh RD, Dhande DJ, Sachdeva KS, Sreenivas A, Kumar AMV, Satyanarayana S, et al. Patient and provider reported reasons for lost to follow up in MDRTB treatment: A qualitative study from a drug resistant TB Centre in India. PLoS One. 2015;10(8):1-11.

27. Shringarpure KS, Isaakidis P, Sagili KD, Baxi RK, Das M, Daftary A. "When treatment is more challenging than the disease": A qualitative study of MDR-TB patient retention. PLoS One. 2016;11(3):112.

28. Kelly, AM; Smith B. Discordance between patient and clinician report of MDR-TB adverse drug reaction. Int J Tuberc Lung Dis. 2016;20(4):442-7.

29. Allen EN, Mushi AK, Massawe IS, Vestergaard LS, Lemnge M, Staedke SG, et al. How experiences become data: the process of eliciting adverse event, medical history and concomitant medication reports in antimalarial and antiretroviral interaction trials. BMC Med Res Methodol. 2013 Dec 14;13(1):140.

30. Corser W, Sikorskii A, Olomu A, Stommel M, Proden C, Holmes-Rovner M. \&quot;Concordance between comorbidity data from patient self-report interviews and medical record documentation\&quot; BMC Health Serv Res. 2008 Dec 16;8(1):85.

31. Pakhomov S V, Jacobsen SJ, Chute CG, Roger VL. Agreement between patient-reported symptoms and their documentation in the medical record. Am J Manag Care. 2008 Aug;14(8):530-9.

32. Ani C, Bazargan M, Hindman D, Bell D, Farooq MA, Akhanjee L, et al. Depression symptomatology and diagnosis: discordance between patients and physicians in primary care settings. BMC Fam Pract. 2008 Dec 3;9(1):1.

33. Bhardwaj P, Deshkar AM, Verma R. Side Effects Encountered in Treatment of Multidrug-resistant Tuberculosis: A 3-Year Experience at First Dots Plus Site of Chhattisgarh. Int J Sci Study. 2015;3(5):104-7.

34. Vashrambhai Patel S, Kapil Bhikhubhai N, Bhimabhai patel A, Samrat Shringarpure K, Gautambhai Mehta K, Krishnakumar Shukla L. Adverse Drug Reactions in Patients put on Multi Drug Resistant 
Tuberculosis (MDR-TB) Treatment in Seven Districts of Central Gujarat. J Young Pharm. 2015;7(4s):42531.

35. Berger SI, lyengar R. Role of systems pharmacology in understanding drug adverse events. Wiley Interdiscip Rev Syst Biol Med. 2011;3(2):129-35.

36. World Health Organization (WHO). WHO | Pharmacovigilance [Internet]. WHO. World Health Organization; 2015 [cited 2019 Apr 30]. Available from: https://www.who.int/medicines/areas/quality_safety/safety_efficacy/pharmvigi/en/

37. Hire R, Kale AS, Dakhale GN, Gaikwad N. A prospective, observational study of adverse reactions to drug regimen for multi-drug resistant pulmonary tuberculosis in central India. Mediterr J Hematol Infect Dis. 2014;6(1).

38. Khan S, Goyal C, Chandel N, Rafi M. Knowledge, attitudes, and practice of doctors to adverse drug reaction reporting in a teaching hospital in India: An observational study. J Nat Sci Biol Med. 2013 Jan;4(1):191.

39. Jose J, Jimmy B, Al-Ghailani ASH, Al Majali MA. A cross sectional pilot study on assessing the knowledge, attitude and behavior of community pharmacists to adverse drug reaction related aspects in the Sultanate of Oman. Saudi Pharm J. 2014 Apr;22(2):163-9.

40. Belton KJ, Lewis SC, Payne S, Rawlins MD, Wood SM. Attitudinal survey of adverse drug reaction reporting by medical practitioners in the United Kingdom. Br J Clin Pharmacol. 1995 Mar;39(3):223-6.

41. Jose J, Jimmy B, Al-Mamari MNS, Al-Hadrami TSN, Al-Zadjali HM. Knowledge, Beliefs and Behaviours Regarding the Adverse Effects of Medicines in an Omani Population: Cross-sectional survey. Sultan Qaboos Univ Med J. 2015 May;15(2):250-6.

42. Babu R, Soundappan K, Anand T, Chadha S. Challenges in management of tuberculosis under programmatic conditions:Perceptions of health care providers from four states of India. Indian $\mathrm{J}$ Community Heal. 2017;29.

43. Fuady A, Houweling TAJ, Mansyur M, Richardus JH. Catastrophic total costs in tuberculosis-affected households and their determinants since Indonesia's implementation of universal health coverage. Infect Dis Poverty. 2018 Dec 12;7(1):3.

44. De-Loyde KJ, Harrison JD, Durcinoska I, Shepherd HL, Solomon MJ, Young JM. Which information source is best? Concordance between patient report, clinician report and medical records of patient comorbidity and adjuvant therapy health information. J Eval Clin Pract. 2015;21(2):339-46.

\section{Tables}


Table:-1 Socio-demographic, behavioral and clinical characteristics of patients with DR-TB initiated on treatment under the RNTCP at DR-TB Center, Gujarat(July-September-2018) 
Characteristics

Mean (SD) age in years

Gender

Education

Education

Education

Area of residence

Socio-Economic Status

Socio-Economic Status

Addiction

Co-morbidities

\begin{tabular}{|l}
\hline \\
\hline Previous TB \\
\hline Drug resistant \\
\hline Health care facility opted for injectables \\
\hline
\end{tabular}

Female

Illiterate

Up to secondary school

Above secondary school 15

Rural

Urban

Above Poverty Line

Below Poverty Line

Not known

No addiction

Tobacco chewing

Smoking

Alcohol

Refused

None

Renal disease

Cardiovascular system

Diabetes

HIV

Liver disease

Othersa

Yes

No

Mono Isoniazid

Multi Drug

Public healthcare

Page $15 / 22$
$\mathrm{N}=74$

(\%)

$32.4( \pm 13.6)$

44

30

13

46

14

60

17

54

03

55

13

09

05

03

50

12

10

8

6

04

04

64

10

24

50

32 
Private health care

Non-injectable regimen
32

10
(43.2)

(13.6)

a Hypothyroidism (2) and Paraplegia (2)

\section{Table:-2}

Socio-demographic, behavioral and clinical characteristics associated with treatment seeking behavior for Adverse events by patients initiated on DR-TB treatment under the RNTCP at DR-TB Center, Gujarat(JulySeptember-2018) 
Characteristic

Treatment sought
Treatment

not

sought

\begin{tabular}{|c|c|c|c|c|c|c|c|c|}
\hline & & $\mathbf{n}$ & (\%) & $\mathrm{n}$ & $(\%)$ & $\mathrm{n}$ & (\%) & \\
\hline Total & & 43 & & 31 & & 74 & & \\
\hline \multirow[t]{2}{*}{ Sex } & Male & 26 & $(59.1)$ & 18 & $(40.9)$ & 44 & $(59.5)$ & 0.83 \\
\hline & Female & 17 & $(56.7)$ & 13 & $(43.3)$ & 30 & $(40.5)$ & \\
\hline \multirow[t]{3}{*}{ Education } & Illiterate & 12 & $(92.3)$ & 1 & (7.7) & 13 & $(17.6)$ & $0.06 a$ \\
\hline & $\begin{array}{l}\text { Up to } \\
\text { secondary }\end{array}$ & 24 & $(52.2)$ & 22 & $(47.8)$ & 46 & $(62.2)$ & \\
\hline & > Secondary & 7 & $(46.7)$ & 8 & (53.3) & 15 & $(20.2)$ & \\
\hline \multirow[t]{3}{*}{ Occupation } & $\begin{array}{l}\text { Home- } \\
\text { maker }\end{array}$ & 3 & $(60.0)$ & 2 & $(40.0)$ & 5 & (6.7) & $0.91 a$ \\
\hline & Unemployed & 8 & (53.3) & 7 & $(46.7)$ & 15 & $(20.0)$ & \\
\hline & Employed & 32 & (59.3) & 22 & $(40.7)$ & 54 & (73.3) & \\
\hline \multirow[t]{2}{*}{ Residence } & Rural & 9 & $(64.3)$ & 5 & $(35.7)$ & 14 & (18.9) & 0.82 \\
\hline & Urban & 34 & $(56.7)$ & 26 & $(43.3)$ & 60 & $(81.1)$ & \\
\hline \multirow{3}{*}{$\begin{array}{l}\text { Socio } \\
\text { Economic } \\
\text { Status }\end{array}$} & $\begin{array}{l}\text { Above } \\
\text { poverty line }\end{array}$ & 9 & $(52.9)$ & 8 & $(47.1)$ & 17 & $(23.0)$ & $\begin{array}{l}0.94 \\
a\end{array}$ \\
\hline & $\begin{array}{l}\text { Below } \\
\text { poverty line }\end{array}$ & 32 & (59.3) & 22 & $(40.7)$ & 54 & $(73.0)$ & \\
\hline & Not known & 2 & $(66.7)$ & 1 & (33.3) & 3 & $(4.0)$ & \\
\hline \multirow[t]{2}{*}{$\begin{array}{l}\text { Drug } \\
\text { resistant }\end{array}$} & $\begin{array}{l}\text { Mono } \\
\text { Isoniazid }\end{array}$ & 15 & (62.5) & 9 & (37.5) & 24 & (32.4) & 0.76 \\
\hline & $\begin{array}{l}\text { Multidrug } \\
\text { resistant }\end{array}$ & 28 & $(56.0)$ & 22 & $(44.0)$ & 50 & $(67.6)$ & \\
\hline \multirow[t]{2}{*}{$\begin{array}{l}\text { Past history } \\
\text { of TB }\end{array}$} & Yes & 38 & $(59.4)$ & 26 & $(40.6)$ & 64 & $(86.5)$ & 0.57 \\
\hline & No & 5 & $(50.0)$ & 5 & $(50.0)$ & 10 & (13.5) & \\
\hline
\end{tabular}




\begin{tabular}{llllllllll}
$\begin{array}{l}\text { Co- } \\
\text { morbidities }\end{array}$ & Present & 11 & $(45.8)$ & 13 & $(54.2)$ & 24 & $(32.4)$ & 0.40 \\
\hline & Absent & 32 & $(64.0)$ & 18 & $(36.0)$ & 50 & $(67.6)$ & \\
\hline Addiction & Yes & 11 & $(57.9)$ & 8 & $(42.1)$ & 19 & $(25.7)$ & 0.87 \\
\hline & No & 32 & $(58.2)$ & 23 & $(41.8)$ & 55 & $(74.3)$ & \\
\hline $\begin{array}{l}\text { Healthcare } \\
\text { facility opted } \\
\text { for injectable } \\
\text { treatment }\end{array}$ & $\begin{array}{l}\text { Public } \\
\text { healthcare }\end{array}$ & 15 & $(46.9)$ & 17 & $(53.1)$ & 32 & $(43.2)$ & 0.67 \\
\hline & $\begin{array}{l}\text { Private } \\
\text { health care }\end{array}$ & 23 & $(71.9)$ & 9 & $(28.1)$ & 32 & $(43.2)$ & \\
\hline & $\begin{array}{l}\text { Not } \\
\text { Applicable }\end{array}$ & 5 & $(50.0)$ & 5 & $(50.0)$ & 10 & $(13.6)$ & \\
\hline & & & & & & & & \\
\hline
\end{tabular}

\# derived by applying chi-square test with Yate's correction\}

Table 3. Perception and challenges regarding reporting of adverse events related to DR-TB treatment from the health providers' and patient's perspective. 


\section{Themes Sub-theme Verbatim quotes}

Health

system

related

Provider Acceptance and related neglect of the AEs

Stigma and discrimination towards patients

Health care facility related
Poor capacity and no Standard Operating Procedures

"Side effects, which will be definitely there, as it is MDR TB, I counselled (my)best to the patients to continue the drug as they will be get used to side effects eventually"(36 male, STS, Rural)

"There is no other treatment regimen available free of cost, patients have to complete course or have to die with TB." (28 Male, DOTS provider, Urban)

"They are defaulters, they always complain more and adhere less to prescribed medicines" (39, Male DOTS provider, Urban)

"When I visited the eye department in district hospital, the nurse asked me to maintain distance from other patients as she realized I am a TB patient." (44, male patient Urban)

"I always ask them to contact medical facility, but defaulters have tendency to no believe in what we say..." (42, Male DOTS provider)

"Whenever, we asked for help regarding side effects, he (DOTS provider) directly refers me to district hospital which is far and not worth attending, they take lots of time and send me from one department to another department." (50, Female patient, Urban)

"She (DOTS provider) sent me to ANM then to PHC and lastly to district hospital, why not (send me) directly there, it took me seven days to get proper care" (35, Male patient, Rural)

"I rarely attend any MDR TB cases, they have such a complicated treatment regimen, I always refer them directly to higher centre or give them some antacids, nothing can be done at PHC." $(41$, female MO,PHC Rural)

Lack of coordination between DR-TB centre and hospital

"We know, the patients have to suffer a lot in tertiary care centre for $A E$ management, but we have to send them to concerned department for consultation." (36 Male, program manager, Urban)

"With multiple referrals in government hospitals, patient have to come back without being attended many times due to high load of patients. It would be better to have special OPD for them" (44 Male, program manager, Urban)

Program Lack of

related guideline and training for $\mathrm{AE}$ identification and management
"I want to help patients, but I am not sure what I can do at my level for such a disease"(38,Female DOTS provider-Nurse Urban)

"We could not decide based on symptoms and history alone whether it is really AE or complication of MDR TB."(41, female PHC-MO Rural)
Lack of proper counselling support and empathy
"Medical Officer has scolded me for my repeated complaint of diarrhea and he has asked me to either continue or stop the medicines. Eventually I learned to stop medicines temporarily whenever I do not feel good" (50, Male patient, Urban) 
"Doctor had advised me on the first day of treatment that, being defaulter of TB treatment, I have to bear all side effects of higher dose anti-TB drugs". (50, Female patient, Rural)

Patient Misconceptions "Side effects are good in a way which promises early cure." (21, level Female patient Urban)

"Side effects are sign of effectiveness of drug which is killing power of Bacteria." (62, Male patient Rural)

"Medicines are free for us, why to complaint for that." (64, Female patient Rural)

Previous treatment experience
"I have visited district hospital twice and they took two days for referring me from one department to another for my abdominal pain and lastly, they have given me same tablet which was prescribed by ANM for acidity." (32, Female patient Rural)

"I have visited many times, various clinics, which resulted in no relief. In spite of that, now I stop taking drugs for few days whenever I do not feel good" (44, Male patient, Urban)

Accessibility and affordability

"I am already not able to work and I could not further afford visiting (the) hospital (43, Male patient, Rural)"
"I asked for help regarding skin rashes and ANM referred me to district hospital which is far and time consuming, I cannot afford to lose my day" (18, Male patient, Urban)

"Why to report side effects, doctor will add some more vicious drugs..." (34, male patient Urban)

Nature of

Adverse Event
I was having tinnitus since so many days but I didn't bother for that, once I realized my hearing had reduced , I reported to ASHA the same. (42, Female patient, Rural)

DOTS- Directly Observed Treatment Short course, ASHA- Aaccredited Social Health Activist, STS- Senior treatment supervisor, MO-PHC Medical officer, Primary Health Centre, ANM- Auxiliary Nursing Midwives

\section{Figures}




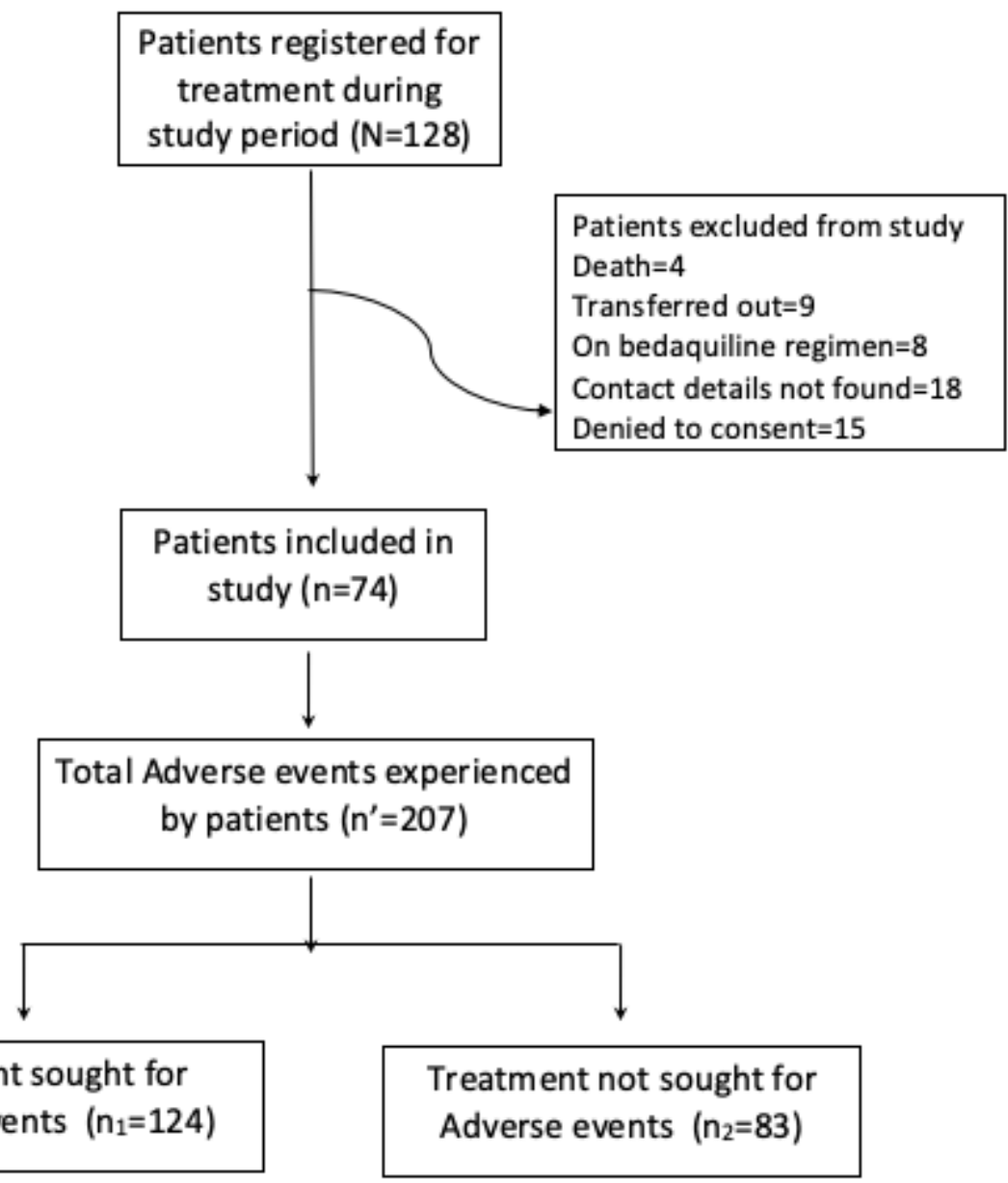

Figure 1

Flow of recruitment, $A E$ experience and treatment seeking for management among patients initiated on DR-TB treatment under the RNTCP at DR-TB Center, Gujarat(July-September-2018)

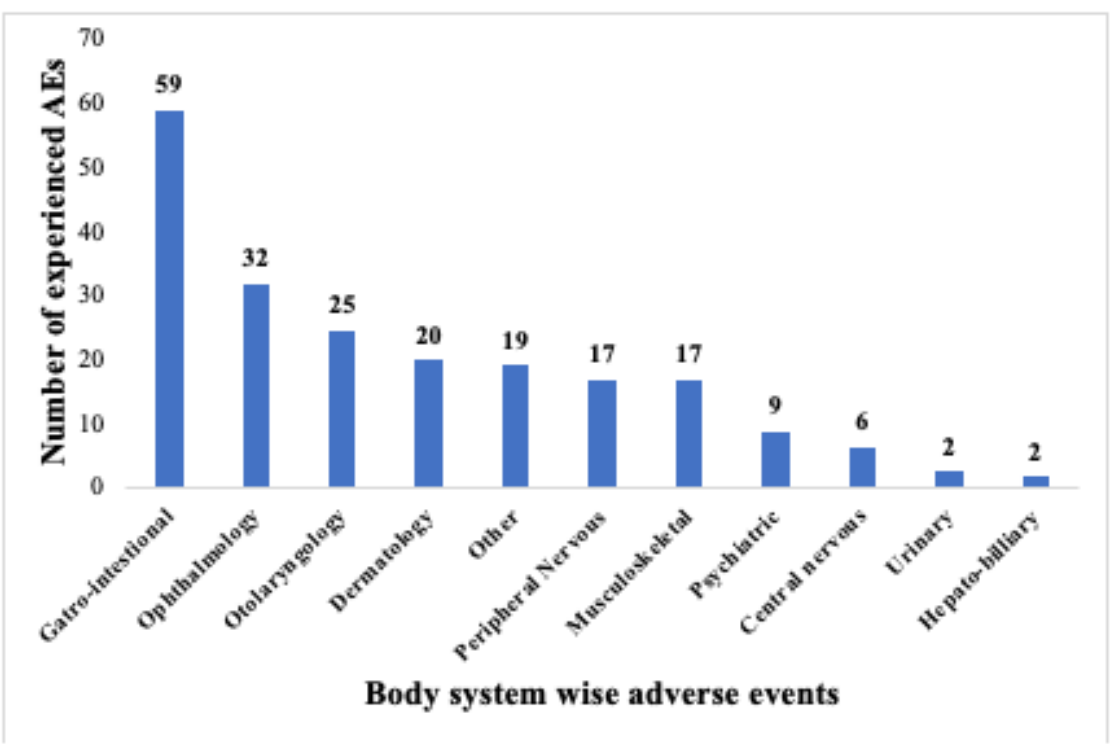


Figure 2

System wise distribution of adverse events $(n=207)$ experienced by patients during first three months of DR-TB treatment under the RNTCP at DR-TB Center, Gujarat(July-September-2018) \{Other includes:Weight loss, Weight gain, Body weakness, Hair loss, Bitterness and dryness of mouth, Menstruation irregularity, Restlessness, Dehydration, Oral cavity rash, Flu, Neck swelling, Headache, Palpitation, Pale look\}

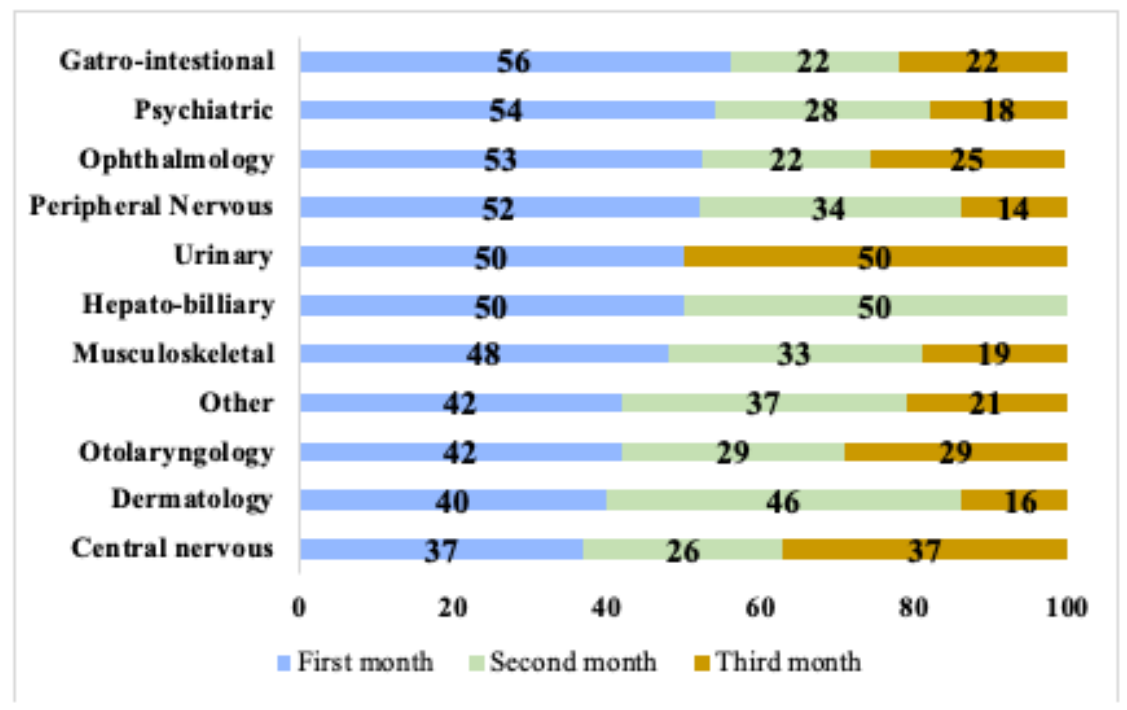

\section{Figure 3}

Pattern and month wise distribution of adverse events experienced by patients during first three months of DR-TB treatment under the RNTCP at DR-TB Center, Gujarat(July-September-2018) \{Other includes:Weight loss, Weight gain, Body weakness, Hair loss, Bitterness and dryness of mouth, Menstruation irregularity, Restlessness, Dehydration, Oral cavity rash, Flu, Neck swelling, Headache, Palpitation, Pale look\}

\section{Supplementary Files}

This is a list of supplementary files associated with this preprint. Click to download.

- FIGUREDATA.xIsx

- SupplementaryTables.pdf 